\title{
UNDERSTANDING THE EFFECTS OF TOXIC LEADERSHIP ON EXPATRIATES' READINESS FOR INNOVATION: AN UZBEKISTAN CASE
}

\author{
Ettiene Paul Hoffman \\ Canadian University Dubai \\ Rommel Pilapil Sergio \\ Canadian University Dubai
}

\begin{abstract}
Ever-growing business challenges emphasize the necessity for organizations to develop a competent workforce to achieve more stable and inclusive growth. Therefore, this study explored the ever-growing interest in expatriate workers to support organizational competitiveness. This study focuses on Uzbekistan, as its growing competitiveness is pressurizing leader-follower dyads and organizational innovation capabilities to improve productivity, reduce costs, and become more profitable. Workplace environments can be sensitive towards leadership behaviours that can adversely affect expatriates' readiness for innovation. Therefore, this research study addressed the gap in empirical evidence within the leadership literature relevant to the interplay between toxic leadership and expatriates' readiness for innovation. This qualitative descriptive study employed an explorative phenomenological cross-sectional design ( $n=10)$ into expatriates' real-life experiences to understand the effects of toxic leadership on their readiness for innovation. The findings from the phenomenological study suggest that toxic leadership can adversely affect expatriate's readiness for innovation.
\end{abstract}

Keywords: toxic leadership, phenomenology, innovation, expatriate, Uzbekistan

DOI: http://dx.doi.org/10.15549/jeecar.v7i1.360

\section{INTRODUCTION}

Uzbekistan, after years of isolation, is progressively addressing its economic challenges and exploiting its inherent strengths as a resource-rich market by positioning itself as a stronger player in the global economy (Bland, 2019; Global Markets, 2019). Consequently, dynamic and growing business environments are inspiring expatriate mobilization through ever increasing assigned and self-initiated expatriation.

Hence, this study as the first empirical attempt in Uzbekistan explored the effect of toxic leadership on self-initiated and company assigned expatriates' readiness for innovation. Expatriate assignments can offer an exciting 
international opportunity and cross-cultural adventure with several advantages that can include personal development, international job mobility, career advancement, skill acquisition, and financial benefits (O'Donohue, Hutchings, \& Hansen, 2018). Conversely, expatriate experiences can attract several drawbacks that manifest in for example social and family tension, culture shock, unfair treatment, bullying, stress, ill-treatment, loss of status, job insecurity, and a high degree of uncertainty (Andresen, Bergdolt, Margenfeld, \& Dickmann, 2014; AlMazrouei \& Zacca, 2015).

The implications point to the sensitivity of the relationship between expatriate follower and direct supervisor. Therefore, to lead organizations responsibly is vital as leadership can favorably or unfavorably affect workplace climates, productivity, turnover intentions, and innovative work behaviors (Service \& Guess, 2015; Metha \& Maheshwari, 2013; Schyns \& Schilling, 2013, Service and Kennedy, 2012, Service, 2012).

With the foregoing statements, it is indeed interesting to thresh out and explore the contextual influences of toxic leadership practices that can affect well-being, performance, and innovative work behaviors among expatriates.

\section{REVIEW OF LITERATURE}

This section includes two parts and explores the concepts that include toxic leadership and innovation. Each part states the importance and implications when exploring the concepts relevant to an expatriate context within an organization.

\section{Toxic Leadership}

Social sciences tend to take a one-sided view of leadership by focusing primarily on its positive aspects (Aasland, Einarsen, Hetland, Matthiesen, Nielsen, \& Skogstad, 2014; Haynes, Hitt, \& Campbell, 2015; Schyns \& Schilling, 2013). Thus, contextual influences such as innovation can be particularly sensitive to toxic leadership practices that can affect followers' well-being, motivation, and innovative work behaviors (Çekmecelioğlu \& Özbağ, 2014; Goffin
\& Mitchell, 2010; Tepper, Moss, \& Duffy, 2011; Tidd \& Bessant, 2009).

\section{Boundaries and Toxic Characteristics}

A unified definition for toxic leadership is not representative within the leadership literature that could clarify boundaries and toxic characteristics (Grandy \& Starratt, 2010; Shaw, Erickson, \& Harvey, 2011). However, in this study, we selected three appropriate toxic leadership constructs based on their potential relevance to the present phenomenological study within an expatriate context (Einarsen, Aasland, \& Skogstad, 2007; Goldman, 2008; Krasikova, Green, \& LeBreton, 2013).

\section{Construct One}

"The systematic and repeated behavior by a leader, superior or manager that violates the legitimate interest of the organization, by undermining and/or sabotaging the organization's goals, tasks, resources and effectiveness, and/or the motivation, well-being or job satisfaction of subordinates" (Einarsen et al., 2007, p. 208).

\section{Construct Two}

"Leader toxicity is an insidious and pernicious spreading of negative emotional contagion - a toxic process accelerated by highly destructive and dysfunctional leadership behavior. In a circular fashion, the diffusion of dysfunction perpetuates organizational systems causing high levels of toxicity, and in turn create new pockets of dysfunction" (Goldman, 2008, p. 245).

\section{Construct Three}

"Volitional behavior by a leader that can harm or intend to harm the leader's organization and/or followers by (a) encouraging followers to pursue goals that contravene the legitimate interest of the organization and/or (b) employing a leadership style that involves harmful methods of influence with followers, regardless of justifications for such behavior" (Krasikova et al., 2013, p.3). Therefore, terminology that signifies negative perceptions about leadership such as abusive, destructive, 
bad, deviant, inept, dysfunctional, divisive, and unethical enters the lexicon of toxic leadership and apply interchangeably.

\section{Construct Evaluation}

Firstly, Einarsen et al. (2007) emphasize that enduring destructive leadership behaviors could adversely affect outcomes for both follower and the organization. Therefore, leaders' misuse of power can adversely affect followers' job satisfaction, commitment, and morale (Inyang, 2013; Schyns \& Schilling, 2013). Furthermore, dysfunctional behaviors cause workplace distress by undermining and/or sabotaging the well-being and autonomy of followers. As expatriate followers need to be confident, enthusiastic, and competent in highly competitive environments, toxic leadership can adversely affect followers' performance (AlMazrouei \& Zacca, 2015; Krasikova et al., 2013).

Secondly, Goldman's (2008) conceptualization of toxic leadership underlines the character flaws of destructive leaders who are incompetent to develop self- and social awareness to manage their own and others' emotions. Toxic leaders can be inept to develop trusting, supportive, engaging, and healthy interpersonal relationships (Holton \& Bøllingtoft, 2015). Furthermore, the implications emphasize that distress and harm can cause the continuous spreading of negative emotional contagion within the workplace. Additionally, harmful emotional negativity could continue to last even after a toxic incident occurred (Goldman, 2008). Consequently, such harmful emotional contagion can cause followers severe distress that can adversely affect followers' work behaviors towards innovation.

Expatriates exposed to toxicity might not be able to change jobs that easily due to insecurities, lack of support, or financial responsibilities (Rosenbusch \& Cseh, 2012). Therefore, workplace distress could last for long periods that can negatively affect expatriates' motivation, job satisfaction, and organizational competitiveness (Schyns \& Schilling, 2013; Too \& Harvey, 2012). Thus, job dissatisfaction and toxic workplaces can decrease productivity and increase followers' turnover intentions (Sergio \& Rylova, 2018).

Thirdly, Krasikova et al. (2013) concur with the harmful consequences that destructive leadership can produce within the workplace. In addition, Krasikova et al. emphasize leaders' intentions to harm can involve pre-meditated devious intents, thoughts, and actions that can cause serious distress and or financial losses. Thus, the implications emphasize that in an expatriate environment, such as Uzbekistan, where trusting and collaborative teamwork are of paramount importance, the intention to harm can irreversibly damage leader-follower dyads.

Furthermore, by reviewing the preceding constructs of toxic leadership, corresponding toxic characteristics include (a) an underlying neglect for the well-being of followers that can be abusive, manipulative, and harmful, (b) micro-management that suffocate followers, (c) overly self-centeredness, and (d) lack of emotional intelligence (Dabke, 2016; Einarsen et al., 2007; Godkin \& Allcorn, 2011; Goldman, 2008).

Similarly, Thoroughgood, Padilla, Hunter, \& Tate (2012) suggest common toxic leadership characteristics that can include, for example, (a) over control, manipulation, intimidation, and force, rather than inspiration and collaboration, (b) behaviors that are seldom absolute or entirely destructive (c) leaders' behaviors which can include both bad and good characteristics, (d) toxicity that can compromise the quality of life (e) behaviors which can cause distraction from goal achievement, and (f) behaviors which can fuel the toxic interplay between dysfunctional leaders, susceptible followers, and corrupt environments ([i.e., toxic triangle], Padilla, Hogan, \& Kaiser, 2007).

These implications emphasize the destructiveness of the toxic triangle to leaderfollower dyads and to organizational performance. Thus, toxic leadership as a physical or verbal, passive or active, indirect or direct phenomenon can adversely affect individuals, groups, and organizations (Haynes et al., 2015; Hershcovis \& Reich, 2013; Tepper et al., 2011). 


\section{Innovation}

Demanding business environments in Eurasian countries necessitate ongoing innovation to cope with competitive market demands. Consequently, innovation emerges as a vital characteristic associated with success (Tidd \& Bessant, 2009). However, despite the vital importance of innovation, the degree of innovation within Uzbekistan is still low (Khasanovna, 2019). These implications emphasize that the focus on innovation as a strategic business driver necessitates follower participation and responsive leadership (Calabrese \& Costa, 2015; De Spiegelaere, Van Gyes, De Witte, Niesen, \& Van Hootegem, 2014; Gomes, Curral, \& Caetano, 2015; Service, 2012). Correspondingly, responsive leadership embraces disciplined, transparent, compassionate, trustworthy, sociable, and proactive behaviors to develop innovative organizations (Millier \& Bellamy, 2014). Furthermore, ongoing action and reflection are required from organizational leaders to support organizational learning and development (Bowerman, 2018).

In addition, for multinational organizations to develop and sustain market competitiveness requires a clear competitive strategy, resultoriented, motivated, informed, future-oriented, and a competent expatriate workforce to embrace effective innovation (Hoffman, 2018). Innovation can relate to something totally new or towards the improvement of existing ideas, products, processes, procedures, and services. Technological innovation is a major driver of economic growth, value creation, productivity, and competitiveness. Therefore, the global arena will not accommodate non-innovative organizations to survive over prolonged periods of time (Goffin \& Mitchell, 2010).

Thus, for innovation to survive, followers need to feel inspired, confident, and competent to participate in driving innovative initiatives. Correspondingly, employees' innovative work behaviors can enhance effective decisionmaking and organizational competitiveness (Sergio \& Rylova, 2018). A positive and enthusiastic state of mind is necessary to drive innovative organizational competitiveness (Abdullatif, Johari, \& Adnan, 2016; Al-Madadha \& Koufopoulos, 2014).
Similarly, a supportive work environment can encourage employees to cope better with organizational demands, while practicing teamwork, pursuing their collective goals, managing, and resolving conflict (Sergio, Ormita, Dungca, \& Gonzales, 2015). Therefore, to encourage followers' readiness for innovation, leaders have a responsibility to uphold ethical principles and moral intentions that can encourage and sustain ethical intentionality in the workplace (Millier \& Bellamy, 2014).

However, a paucity of scholarly studies exists regarding the relationships between toxic leadership and innovation (Calabrese \& Costa, 2015; Holton \& Bøllingtoft, 2015). Historically, leadership research primarily examined the influence of leadership on job satisfaction and motivation (Bhatnagar, 2012; Çekmecelioğlu \& Özbağ, 2014). Therefore, the current research study addresses the theoretical and empirical gabs by adding to the body of leadership knowledge relevant to the interplay between toxic leadership and innovation within an expatriate context.

\section{RESEARCH OBJECTIVES}

In contemporary organizations, toxic leadership, an understudied phenomenon, can be a prevalent destructive reality by causing vast financial losses, workplace distress, and follower disengagement (Eesley \& Meglich, 2011; Mowchan, Lowe, \& Reckers, 2015). Empirical research suggests that the base rate of leaders exhibiting destructive behaviors can be as high as $80 \%$, which can cost organizations millions in lost productivity (Aasland et al., 2014; Krasikova et al., 2013). With this in mind, the following objectives were raised:

- To determine expatriates' view of the effects of toxic leadership on their readiness for innovation.

- To determine emerging themes from expatriates' views regarding the effects of toxic leadership on their innovative work behaviors. 


\section{METHODOLOGY}

\section{Sampling}

To address saturation of data relevant to the phenomena of interest, homogenous, nonprobability, and purposive sampling as opposed to random probability sampling was applied, to conduct the in-depth semi-structured interviews. Furthermore, non-probability sampling was applied, as the objective was to pursue saturation of qualitative data rather than to maximize statistical numbers (Creswell, 2014). Furthermore, homogenous instead of heterogeneous sampling was applied, as the former included participants with previous experiences of the phenomena of interest that afforded richer descriptions of the targeted population's lived experiences.

Purposive sampling incorporated specific criteria that participants had to meet at the time of selection. Thus, criteria sampling supported the purposive, non-probability, and homogenous sampling strategy by identifying potential participants who met specific selection characteristics. Hence, the following criteria applied: (a) had experience working with or reporting to a destructive organizational leader for at least two years in Uzbekistan, (b) prepared to participate anonymously, transparently, and voluntary in English by sharing their lived experiences concerning the phenomena of interest, and (c) answer prequalifying questions to ascertain participants' suitability and intention to participate.

The Uzbekistan context is viewed as businessfriendly that embraces a developing infrastructure, capable workforce, and the support of a competitive operating cost structure. Additionally, the government emphasizes the significance of attracting foreign direct investment (FDI) to sustain economic growth and transformation (Bland, 2019).

The targeted population included expatriate working professionals, on a long-term mission in supervisory positions, across diverse industries that included organizations within the textile, manufacturing, and industrial sectors. General characteristics of the multinational organizations encompassed small to medium size enterprises as permanent establishments with objectives to drive sustained competitiveness by blending headquarter management conformance and innovative performance. Participants' sample included six (60\%) males and four (40\%) females, within the age range 25-52, and representing European and Russian ethnicities.

\section{Data Collection Method}

The study included 10 face-to-face semistructured interviews to explore the phenomena of interest within an expatriate context in Uzbekistan. Moreover, the semistructured interviews suited the ontological and epistemological qualitative research paradigm, as an insider's idealistic and subjective view applied to obtain saturation of quality authentic data. Therefore, the focus was on specific characteristics of the targeted population. By exploring the multiple realities of a small number of expatriates who had previously experienced the phenomena of interest, we could gain rich descriptions of their lived experiences to enhance understanding of the phenomena of interest. The open-ended interview questions took inspiration from a validated survey instrument, the Destructive Leadership Questionnaire ([DLQ], Shaw et al., 2011). The DLQ identifies toxic or dysfunctional leadership behaviors by asking subordinates and peers to identify specific destructive behaviors a leader exhibit.

\section{Data Analysis Method}

Thematic analysis embraced verbal protocol analysis to identify appropriate emerging themes from the interview data as expressed in the dialogue by the participants. A tentative a priori codes framework based on the DLQ applied and informed the data analysis in exploring the stated research objectives. The semi-structured interviews encouraged verbal protocol analysis as participants were encouraged to think aloud, while reflecting and sharing their real-life experiences relevant to the phenomena of interest. The researchers examined the verbal protocols, identified emerging themes, and compared them to the a priori codes, as shown in appendices 1 to 4.Data analysis pursued a rigorous, non-linear, attentive, systematic identification, and clustering of data into common themes 
ensuring minimized bias to enhance trustworthiness of the study. Furthermore, as part of the verbal protocol analysis, three experts reviewed the mapping of the interview data and concurred on the alignment of emerging themes and a priori codes. The data analysis framework embraced phenomenological reduction that included bracketing, horizontalization, organizing themes, and building of textural descriptions (Creswell, 2014).

Subsequently, emerging themes were clustered and compared with the a priori codes framework that included four overarching DLQ dimensions (Olls, 2014; Shaw et al., 2011):

- Managerial Ineffectiveness (MI, [Theme 1]), as shown in Appendix 1.

- Interpersonal Harshness (IH, [Theme 2]), as shown in Appendix 2.

- Laissez-Faire (LF, [Theme 3]), as shown in Appendix 3.

- Indecisiveness/Inaction (II, [Theme 4]), as shown in Appendix 4.

\section{RESULTS AND DISCUSSION}

In this section of the report, the researchers present expatriates' understanding of the impact of toxic leadership on their readiness for innovation. Furthermore, ad verbatim excerpts from the semi-structured face-to-face interviews have been included to demonstrate expatriates' real-life experiences with the phenomena of interest within the workplace.

\section{The Effects of Toxic Leadership}

Findings relevant to the stated objectives suggest that toxic leadership adversely affected expatriates' readiness for innovation. Commonalities were clustered and include occurrences of the number of times participants' data descriptions matched the chosen themes. Thus, the study clustered occurrences as per the four themes of toxic leadership that included MI (Theme 1: 89 occurrences), IH (Theme 2: 82 occurrences), LF (Theme 3: 68 occurrences), and II ([Theme 4: 74 occurrences]).

Participant's Excerpts Relevant to MI (Theme 1)
MI explored managerial actions that may cause workplace toxicity and affect innovative work behaviors. Therefore, MI included the following features: (a) not seeking followers' opinions, (b) not supporting followers, (c) poor partnerships, (d) failure to provide resources, and (e) not motivating followers.

My manager never asks for my opinion... I find it demotivating to work in an environment where my opinion is not valued... I do not feel encouraged to participate, as my manager rarely respond when I ask for assistance... I feel my manager discriminates between workers... My manager is taking credit for work that I have done... My manager always looks for mistakes...

The findings suggest that MI (Theme 1) caused lack of interest towards innovative work behavior, lack of available resources, and lack of participants' motivation due to unfavorable workplace environments. In addition, ineffective leaders did not appreciate participants' efforts, which created negativity and disengagement within the workplace. Implications from the participants' responses indicated poor leaderfollower dyads as management did not seek out or act upon participants' feedback or recommendations. Therefore, strained leaderfollower dyads adversely affected participants' participation and readiness for innovation. Hence, the findings concur with academicians that social skills are imperative to develop inspiring workplace environments (Aasland et al., 2014; Goldman, 2008; Sergio \& Rylova, 2018).

\section{Participants' Excerpts Relevant to IH (Theme 2)}

IH explored managerial actions that may cause workplace toxicity and affect innovative work behaviors. IH included the following features: (a) undue working pressure, (b) tyrannical behaviors, (c) disrespectful behaviors, (d) micro-management, and (e) leaders' words and actions not aligned.

My manager changes targets in the middle of a project... Even though I am experienced, my manager is checking all details of my work... My manager is not respecting my time...My manager sets unrealistic goals without my 
involvement... My manager's words and actions are different... I have no empowerment to make any decisions... I feel my manager is deliberately putting me down... My manager is calling me humiliating names...

The findings suggest that IH (Theme 2) caused discomfort to participants that included for example nervousness, tiredness, anxiety, frustration, anger, tension, confusion, negative thoughts, and fear that affected their well-being and readiness for innovation. Implications from participants' responses indicated several toxic leadership behaviors; for example, egoism, disrespect, arrogance, oppressiveness, forcefulness, self-centeredness, hostility, rudeness, exploitation, all knowing, abusiveness, self-serving political intentions, and micro-management.

This finding concurs with scholarly research that workplace toxicity can include the presence of bullying, destructive narcissism, and excessive Machiavellianism (Grandy \& Starratt, 2010; Krasikova et al., 2013; Tepper et al., 2011). In addition, participants' rich descriptions suggested that toxicity adversely affected ethics, job satisfaction, and job security (Haynes et al., 2015; Metha \& Maheshwari, 2013). In addition, feelings of inadequacy and distress discouraged participants to engage in innovative work behaviors (Abdullatif et al., 2016; De Spiegelaere et al., 2014).

\section{Participants' Excerpts Relevant to LF (Theme 3)}

LF explored managerial actions or the absence of managerial actions that may cause workplace toxicity that affect innovative work behaviors. Therefore, LF included the following features: (a) unclear management expectations, (b) no feedback, (c) lack of learning and development, (d) not valuing followers, and (e) absence of leadership.

My manager's instructions are unclear... My manager is not involved... I am not getting feedback about my performance... My manager's lack of direction affects the environment negatively... I often guess what to do... I do not know if my manager is satisfied with my work... My manager never says thank you... Conflict situations are not resolved... I am not getting any recognition...

The findings suggest that LF (Theme 3) represents an absence of leadership that adversely affected participants' readiness for innovation. In addition, the results suggest lack of effective communication that adversely affected teamwork, morale, and collaboration. Furthermore, lack of constructive feedback, direction, and effective role clarification caused ambiguous workplace climates that triggered disengagement. Findings suggest that leaders were repeatedly absent or disengaged to hide their incompetence and insecurities.

Therefore, the research concurs with scholarly research that disengaged leaders contributed towards low morale, poor results, ambiguous environments, and increased workplace hostility (Çekmecelioğlu \& Özbağ, 2014; Einarsen et al., 2007; Millier \& Bellamy, 2014).Implications emphasized that ambiguous environments harbored incompetent and insecure leaders that attracted interference, low productivity, ineffective communication, noncompliance, poor collaboration, delayed decision-making, and lack of innovation (Aasland et al., 2014; Goffin \& Mitchell, 2010; Goldman , 2008; Tidd \& Bessant, 2009; Too \& Harvey, 2012).

\section{Participants' Excerpts Relevant to II (Theme 4)}

II explored managerial actions that may cause workplace toxicity and affect innovative work behaviors. Therefore, II included the following features: (a) difficulty in making decisions, (b) poor problem solving, (c) unwillingness to act, (d) difficulty in dealing with change, and (e) slow to maximize technology.

It is taking a long time to get a decision from my manager... My manager displays no urgency... I feel my manager is deliberately withholding decisions to victimize... My manager is avoiding solving problems... We are in a fast-changing environment; however, my manager is slow to recognize or approve the necessary changes... I have difficulty to manage my team when my manager is slow to respond... My manager is outdated with the latest technology... 
The findings suggest that II (Theme 4) negatively affected participants' readiness for innovation. The implications from participants' responses indicated that perceptions of toxicity can originate from leaders' behaviors to undermine, victimize, and harm. In addition, findings suggested that incompetence and intentions to obstruct workflow can contribute towards, ineffective problem solving, indecisiveness, and workplace distress that triggered disengagement.

The findings suggest that II denoted several elements of toxicity that included for example (a) repeated disruptive behaviors (Grandy \& Starratt, 2010), (b) ineffective resources that affected participants' efficacy (Einarsen et al., 2007), (c) diffusion of negative emotional contagion that caused destructiveness within the workplace (Goldman, 2008), and (d) intentions to victimize, bully, and intimidate (Krasikova et al., 2013; Tepper et al., 2011)

Furthermore, participants' responses suggest that vagueness, inaction, and tainted intentions negatively influenced morale, teamwork, engagement, and innovative work behaviors. Therefore, findings concur that leaders have the responsibility to uphold an ethical code of conduct, sustain unadulterated intentionality, and practice ongoing reflection to improve (Bowerman, 2018; Hoffman, 2018; Millier \& Bellamy, 2014; Mowchan et al. 2015; Sergio et al., 2015).

The implications of themes 1-4 suggest that toxic leaders: (a) can act in self-centered and isolating ways, (b) can ignore important issues, (c) unable to build effective inspiring teams, (d) are inconsistent and unreliable (e) can create ambiguity, (f) are dominating, autocratic, overcontrolling, and (g) can violate trust (Olls, 2014; Shaw et al., 2011; Thoroughgood et al., 2012). Empirical data concur with scholarly research that toxic leadership can include systematic and repeated behaviors to violate, undermine and or sabotage followers' goals, well-being, job satisfaction, and motivation towards innovative work behaviors (Bhatnagar, 2012; De Spiegelaere et al., 2014; Goffin, \& Mitchell, 2010).

\section{CONCLUSION}

The research findings suggest that in contemporary organizational environments, toxic leadership, an understudied phenomenon, can be a persistent destructive reality causing maltreatment, harm, increased turnover intentions, financial losses, and disengagement towards innovative work behaviors. Therefore, the present explorative, cross sectional, and descriptive phenomenological study enhances understanding of the lived experiences of expatriates as it pertains to the effect of toxic leadership on their readiness for innovation.

Considering the first objective, the study concludes that toxic leadership adversely affected expatriates' readiness for innovation. Volatile, uncertain, and competitive business conditions necessitate confident, competent, and result oriented expatriates to engage in innovative work behaviors. Concerning the second objective, results from the interviews revealed the emergence of four distinct themes that included managerial ineffectiveness, interpersonal harshness, laissez-fair, and indecisiveness/inaction. Thematic implications emphasize that ever-increasing complexities within organizations require ethical and inspiring leadership practices to navigate workplace demands.

Consequently, this study's results underpin the importance of positive leader-follower dyads to embrace expatriates' readiness for innovation. The study asserts that toxic leadership can represent a slow acting devious poison that confuses detection by creating ambiguity to hide incompetence, disguises intentions to harm, distorts accountability, and obscures application of a remedy. Thus, the implications emphasize that organizations need to identify, deter, stop, and develop toxic leaders with urgency to encourage ethical and responsible leadership practices.

\section{REFERENCES}

Aasland, M., Einarsen, S., Hetland, J., Matthiesen, S. B., Nielsen, M. B., \& Skogstad, A. (2014). The relative effects of constructive, laissesfaire, and tyrannical leadership on subordinate job satisfaction: Results from two prospective and representative studies. 
Zeitschrift Für Psychologie, 222(4), 221-232. doi:10.1027/2151-2604/a000189

Abdullatif, T., Johari, H. \& Adnan, Z., 2016. The impact of psychological empowerment on innovative work behavior moderating by quality culture. European Journal of Business and Management, 8(7), p. 126-131.

Al-Madadha, A., \& Koufopoulos, D.N. (2014). Linking an integrated approach of empowerment to employee creativity. European Scientific Journal, 2(1), 141-146.

AlMazrouei, H., \& Zacca, R. (2015). Expatriate leadership competencies and performance: A qualitative study. International Journal of Organizational Analysis, 23(3), 404-424. doi:10.1108/IJOA-07-2014-0781

Andresen, M., Bergdolt, F., Margenfeld, J., \& Dickmann, M. (2014). Addressing international mobility confusion: Developing definitions and differentiations for self-initiated and assigned expatriates as well as migrants. International Journal of Human Resource Management, 25(16), 2259-2318. doi:10.1080/09585192.2013.877058

Bhatnagar, J. (2012). Management of innovation: Role of psychological empowerment, work engagement and turnover intention in the Indian context. The International Journal of Human Resource Management, 23(5), 928951. doi:10.1080/09585192.2012.651313

Bland, B. (2019). Uzbekistan Outbound: Central Asia's most populous country is ready to welcome the world. Business Traveler (Middle East Edition), 18-24. Retrieved from http://search.ebscohost.com

Bowerman, J. (2018). Action learning: The need for action and reflection for managers and learners in a world of change. Journal of Eastern European and Central Asian Research, 5(1), 1-7. doi:10.15549/jeecar.v5i1.208

Calabrese, A., \& Costa, R. (2015). Strategic thinking and business innovation: Abduction as cognitive element of leaders' strategizing. Journal of Engineering \& Technology Management, 38, 24-36. doi: 10.1016/j.jengtecman.2015.06.001

Çekmecelioğlu, H.G., \& Özbağ, G. (2014). Linking psychological empowerment, individual creativity and firm innovativeness: A research on Turkish manufacturing industry. Business Management Dynamics, 3(10), 113.

Creswell, J. (2014). Research Design: Qualitative, Quantitative, and Mixed Methods Approaches. Thousand Oaks, CA: Sage.

Dabke, D. (2016). Impact of leader's emotional intelligence and transformational behavior on perceived leadership effectiveness: A multi-source view. Business Perspective \& Research, 4(1), 27-40. doi:10.1177/2278533715605433

De Spiegelaere, S., Van Gyes, G., De Witte, H., Niesen, W., \& Van Hootegem, G. (2014). On the relation of job insecurity, job autonomy, innovative work behavior and the mediating effect of work engagement. Creativity and Innovation Management, 23(3), 318-330. doi:10.1111/caim.12079

Eesley, D., \& Meglich, P. A. (2011). A bully in its own China shop: Risk factors for abusive supervisors in small firms. International Journal of Business and Social Science, 2(19), 11-22. Retrieved from www.ijbssnet.com/

Einarsen, S., Aasland, M. S., \& Skogstad, A. (2007). Destructive leadership behavior: A definition and conceptual model. Leadership Quarterly, 18(3), 207-216. doi: 10.1016/j.leaqua.2007.03.002.

GlobalMarkets. (2019). Uzbekistan: coming in from the cold. Global Capital, N.PAG. Retrieved from http://search.ebscohost.com

Godkin, L., \& Allcorn, S. (2011). Organizational resistance to destructive narcissistic behavior. J Bus Ethics, 104, 559-570. doi:10.1007/s10551-011-0930-x

Goffin, K., \& Mitchell, R. (2010). Innovation management: Strategy and implementation using the pentathlon framework. Basingstoke: Palgrave Macmillan.

Goldman, A. (2008). Consultant and critics on the coach. Journal of Management Inquiry, 17(3), 243-249. doi: $10.1177 / 1056492608318160$

Gomes, C., Curral, L., \& Caetano, A. (2015). The mediating effect of work engagement on the relationship between self-leadership and individual innovation. International Journal 
of Innovation Management, 19(1), 1-19. doi:10.1142/S1363919615500097

Grandy, G., \& Starratt, A. (2010). Young workers' experiences of abusive leadership. Leadership \& Organization Development Journal, 31(2), 136-158. doi:10.1108/01437731011024394

Hammond, M., Neff, N. L., Farr, J. L., Schwall, A. R., \& Zhao, X. (2011). Predictors of individual level innovation at work: A meta-analysis. Psychology of Aesthetics, Creativity, and the Arts, 5(1), 90-105. doi: org/10.1037/a0018556

Haynes, K., Hitt, M. A., \& Campbell, J. T. (2015). The dark side of leadership: Towards a midrange theory of hubris and greed in entrepreneurial context. Journal of Management Studies, 52(4), 479-505. doi:10.1111/joms.12127

Hershcovis, M., \& Reich, T. C. (2013). Integrating workplace aggression research: Relational, contextual, and method considerations. Journal of Organizational Behavior, 34(S1), S26-S42. doi:10.1002/job.1886

Hoffman, E. P. (2018). Ethical HEROES: Develop Responsible and Responsive Leadership Practices that can Enable Engaging, Inspiring, and Ethical Workplace Environments. Chennai, India: Notion Press.

Holton, A., \& Bøllingtoft, A. (2015). Is it only good? The dark side of leadership for creativity and innovation. Journal of Leadership Studies, 9(3), 50-52. doi: $10.1002 / j l s .21403$

Inyang, B. (2013). Exploring the concept of leadership derailment: Defining new research agenda. International Journal of Business and Management, 8(16), 78-85.

Khasanovna, V. M. (2019). Current Tendency of Innovative Activity in the Country and Venture Investment for Uzbekistan. Journal of Accounting \& Finance (2158-3625), 19(1), 53-56. Retrieved from http://search.ebscohost.com

Krasikova, D., Green, S., \& LeBreton, J. (2013). Destructive leadership: A theoretical review, integration, and future research agenda. Journal of Management, 39(5), 1308-1338. doi:10.1177/0149206312471388
Mehta, S., \& Maheshwari, G. (2013). Consequence of toxic leadership on employee job satisfaction and organizational commitment. Contemporary Management Research, 8(2), 1-23.

Millier, K., \& Bellamy, P. (2014). The Businesswoman's Association of Uzbekistan: A qualitative study of the emergence and potential influence of women's leadership in Central Asia. Journal of Eastern European and Central Asian Research, 1(1), 1-9. doi:10.15549/jeecar.v1i1.34

Mowchan, M., Lowe, D. J., \& Reckers, P. J. (2015). Antecedents to unethical corporate conduct: Characteristics of the complicit follower. Behavioral Research in Accounting, 27(2), 95-126. doi:10.2308/bria-51186

O’Donohue, W., Hutchings, K., \& Hansen, S. D. (2018). Psychological contracts: enhancing understanding of the expatriation experience. International Journal of Human Resource Management, 29(8), 1379-1401. https://doi.org/10.1080/09585192.2017.127 8828

Olls, C. (2014). Relations among leader personality traits and subordinates' perceptions of destructive leadership. Raleigh, NC: North Carolina State University (NCSU). Retrieved from http://repository.lib.ncsu.edu/ir/handle/184 $0.16 / 9769$

Padilla, A., Hogan, R., \& Kaiser, R.B. (2007). The toxic triangle: Destructive leaders, susceptible followers, and conducive environments. Leadership Quarterly, 18(1), 176-194. doi: 10.1016/j.leaqua.2007.03.001

Rosenbusch, K., \& Cseh, M. (2012). The crosscultural adjustment process of expatriate families in a multinational organization: A family system theory perspective. Human Resource Development International, 15(1), 61-77. doi:10.1080/13678868.2011.646895

Schyns, B., \& Schilling, J. (2013). How bad are the effects of bad leaders? A meta-analysis of destructive leadership and its outcomes. Leadership Quarterly, 24(1), 138-158. doi: 10.1016/j.leaqua.2012.09.001

Sergio,R.P., \& Rylova, M. (2018). Employee engagement and empowerment as gateway towards retention: The case of Volkswagen 
group. Journal of Eastern European and Central Asian Research, 5(2), 120-130. doi:10.15549/jeecar.v5i2, 242

Sergio, R.P., Ormita, L. G., Dungca, A. L., \& Gonzales, J. O. (2015). Emotional Intelligence, work/family conflict, and work values among customer service representatives: Basis for organizational support. Journal of Eastern European and Central Asian Research, 2(1), 1-9. doi:10.15549/jeecar.v2i1, 86

Service, R.W. (2012). Leadership and innovation across cultures: CIQ-contextual effectiveness as a skill. Southern Business Review, 37(1): 19-50.

Service, R.W., \& Guess, A. K. (2015). Leadership advantage: A people person. Journal of Leadership, Accountability and Ethics, 12(4), 59.

Service, R.W. and K. Kennedy. (2012). A comprehensive global leadership model. The Business Renaissance Quarterly, 7(1): 75106.

Shaw, J., Erickson, A., \& Harvey, M. (2011). A method for measuring destructive leadership and identifying types of destructive leaders in organizations. The Leadership Quarterly, 22, 575-590. doi: 10.1016/j.leaqua.2011.05.001

Tepper, B., Moss, S. E., \& Duffy, M. K. (2011). Predictor of abusive supervision: Supervisor perception of deep-level dissimilarity, relationship conflict, and subordinate performance. Academy of Management Journal, 43, 279-294.

Thoroughgood, C. N., Padilla, A., Hunter, S. T., \& Tate, B. W. (2012). The susceptible circle: A taxonomy of followers associated with destructive leadership. The Leadership Quarterly, 23(5), 897-917. doi: 10.1016/j.leaqua.2012.05.007

Tidd, J., \& Bessant, J. (2009). Managing Innovation: Integrating Technological, Market and Organizational Change. Chichester: Wiley.

Too, L., \& Harvey, M. (2012). Toxic workplaces: The negative interface between the physical and social environments. Journal of Corporate Real Estate, 14(3), 171-181. doi:10.1108/14630011211285834

\section{ABOUT THE AUTHORS}

Ettiene Paul Hoffman, email: ettiene.hoffman@cud.ac.ae

Ettiene Paul Hoffman is an Assistant Professor of Management. He earned a MA in Leading Innovation and Change (with distinction) from the York St John University, United Kingdom and a Doctorate of Management (with distinction) from the Swiss Management Centre University, Switzerland. He is a published book author, management coach, and an experienced Corporate manager. His most recent research interests lie in exploring the causes, behaviors, and outcomes of dysfunctional leadership in organisations.

Rommel Sergio holds a PhD in Management (with high distinction) at the University of Liverpool, UK in 2015 and has earned his PhD in Psychology (with highest distinction) at De La Salle University, Philippines in 2008. He also acquired his Post-Doctoral Bridge to Business in Management certificate at Tulane University, New Orleans, Louisiana, USA in 2011. He is currently the Human Resource Management Program Associate Professor at the Canadian University of Dubai, United Arab Emirates. It can be noted that Dr. Sergio was awarded certified by the AACSB (The Association to Advance Collegiate Schools of Business) in Florida, USA as AQ (Academically Qualified) to teach in Management. He has also published and co-authored several academic research papers that he presented in several international academic conferences, including Harvard University. 


\section{APPENDICES}

Appendix 1: Theme 1: Managerial Ineffectiveness (MI)

\begin{tabular}{|c|c|c|}
\hline \multicolumn{3}{|c|}{ Verbal Protocol Analysis } \\
\hline Participants' verbatim excerpts & Emerging Themes & $\begin{array}{l}\text { A Priori Code relevant to } \\
\text { Theme } 1\end{array}$ \\
\hline My manager never asks for my opinion... & Absence of teamwork & Poor partnership \\
\hline $\begin{array}{l}\text { I find it demotivating to work in an } \\
\text { environment where my opinion is not } \\
\text { valued... }\end{array}$ & Not motivated & Not motivating followers \\
\hline $\begin{array}{l}\text { I do not feel encouraged to participate, as } \\
\text { my manager rarely respond when I ask } \\
\text { for assistance... }\end{array}$ & Not getting support & Not supporting followers \\
\hline $\begin{array}{l}\text { I feel my manager discriminates between } \\
\text { workers... }\end{array}$ & Not getting support & Not supporting followers \\
\hline $\begin{array}{l}\text { My manager is taking credit for work } \\
\text { that I have done... }\end{array}$ & Absence of teamwork & Poor of partnership \\
\hline My manager always looks for mistakes... & Not motivating & Not motivating followers \\
\hline $\begin{array}{l}\text { I hardly have the required tools to } \\
\text { perform my work efficiently... }\end{array}$ & Not having resources & Fails to provide resources \\
\hline $\begin{array}{l}\text { If my manager will make time to speak } \\
\text { with me, we can solve many problems... }\end{array}$ & Absence of teamwork & Poor partnership \\
\hline $\begin{array}{l}\text { I feel my skills are not properly used and } \\
\text { appreciated... }\end{array}$ & Not motivated & Not motivating followers \\
\hline
\end{tabular}

Appendix 2: Theme 2: Interpersonal Harshness (IH)

\begin{tabular}{|l|l|l|}
\hline \multicolumn{3}{|c|}{ Verbal Protocol Analysis } \\
\hline Participants' verbatim excerpts & Emerging Themes & $\begin{array}{l}\text { A Priori Code relevant to } \\
\text { Theme 2 }\end{array}$ \\
\hline $\begin{array}{l}\text { My manager changes targets in the } \\
\text { middle of a project... }\end{array}$ & Excessive work pressure & Undue work pressure \\
\hline $\begin{array}{l}\text { My manager is checking all details of my } \\
\text { work... }\end{array}$ & Micro-managing & Micro-management \\
\hline $\begin{array}{l}\text { My manager is calling me humiliating } \\
\text { names... }\end{array}$ & Disrespecting & Disrespectful behaviors \\
\hline My manager is not respecting my time... & Excessive work pressure & Undue work pressure \\
\hline $\begin{array}{l}\text { My manager sets unrealistic goals } \\
\text { without my involvement... }\end{array}$ & Excessive work pressure & Undue work pressure \\
\hline $\begin{array}{l}\text { My manager's words and actions are } \\
\text { different... }\end{array}$ & $\begin{array}{l}\text { Words and actions nor } \\
\text { corresponding }\end{array}$ & $\begin{array}{l}\text { Leaders' words and } \\
\text { actions not aligned. }\end{array}$ \\
\hline $\begin{array}{l}\text { I have no empowerment to make any } \\
\text { decisions... }\end{array}$ & Micro-managing & Micro-management \\
\hline $\begin{array}{l}\text { I feel my manager is deliberately putting } \\
\text { me down... }\end{array}$ & Oppressive & Tyrannical behavior \\
\hline My manager has threatened me ... & Oppressive & Tyrannical behavior \\
\hline
\end{tabular}


Appendix 3: Theme 3: Laissez-Faire (LF)

\begin{tabular}{|l|l|l|}
\hline \multicolumn{3}{|c|}{ Verbal Protocol Analysis } \\
\hline Participants' verbatim excerpts & Emerging Themes & $\begin{array}{l}\text { A Priori Code relevant to } \\
\text { Theme 3 }\end{array}$ \\
\hline My manager's instructions are unclear... & Uncertain expectations & $\begin{array}{l}\text { Unclear management } \\
\text { expectations }\end{array}$ \\
\hline My manager is not involved... & No leadership & Absence of leadership \\
\hline $\begin{array}{l}\text { I am not getting feedback about my } \\
\text { performance... }\end{array}$ & No feedback & No feedback \\
\hline $\begin{array}{l}\text { My manager's lack of direction affects } \\
\text { the environment negatively... }\end{array}$ & No leadership & Absence of leadership \\
\hline $\begin{array}{l}\text { I often guess what to do... } \\
\text { I do not know if my manager is satisfied } \\
\text { with my work... }\end{array}$ & Uncertain expectations & $\begin{array}{l}\text { Unclear management } \\
\text { expectations }\end{array}$ \\
\hline My manager never says thank you... & No appreciation & No feedback \\
\hline Conflict situations are not resolved... & No leadership & Not valuing followers \\
\hline I am not getting any recognition... & No appreciation & Absence of leadership \\
\hline $\begin{array}{l}\text { I am not getting any job-related } \\
\text { training... }\end{array}$ & $\begin{array}{l}\text { No learning and } \\
\text { development }\end{array}$ & $\begin{array}{l}\text { Lack of learning and } \\
\text { development }\end{array}$ \\
\hline
\end{tabular}

Appendix 4: Theme 4: Indecisiveness/Inaction (II)

\begin{tabular}{|l|l|l|}
\hline \multicolumn{3}{|c|}{ Verbal Protocol Analysis } \\
\hline Participants' verbatim excerpts & Emerging Themes & $\begin{array}{l}\text { A Priori Code relevant to } \\
\text { Theme 4 }\end{array}$ \\
\hline $\begin{array}{l}\text { It is taking a long time to get a decision } \\
\text { from my manager... }\end{array}$ & $\begin{array}{l}\text { Unproductive decision } \\
\text { making }\end{array}$ & $\begin{array}{l}\text { Difficulty in making } \\
\text { decisions }\end{array}$ \\
\hline My manager displays no urgency... & Reluctance to act & Unwillingness to act \\
\hline $\begin{array}{l}\text { I feel my manager is deliberately } \\
\text { withholding decisions to victimize... }\end{array}$ & $\begin{array}{l}\text { Unproductive decision } \\
\text { making }\end{array}$ & $\begin{array}{l}\text { Difficulty in making } \\
\text { decisions }\end{array}$ \\
\hline $\begin{array}{l}\text { My manager is avoiding solving } \\
\text { problems... }\end{array}$ & $\begin{array}{l}\text { Ineffective problem } \\
\text { solving }\end{array}$ & Poor problem solving \\
\hline $\begin{array}{l}\text { We are in a fast-changing environment; } \\
\text { however, my manager is slow to } \\
\text { recognize or approve the necessary } \\
\text { changes... }\end{array}$ & $\begin{array}{l}\text { Unproductive decision } \\
\text { making }\end{array}$ & $\begin{array}{l}\text { Difficulty in dealing with } \\
\text { change }\end{array}$ \\
\hline $\begin{array}{l}\text { I have difficulty to manage my team } \\
\text { when my manager is slow to respond... }\end{array}$ & Reluctance to act & Unwillingness to act \\
\hline $\begin{array}{l}\text { The work environment is negative and } \\
\text { full of conflict... }\end{array}$ & $\begin{array}{l}\text { Ineffective problem } \\
\text { solving }\end{array}$ & Poor problem solving \\
\hline $\begin{array}{l}\text { My manager is outdated with the latest } \\
\text { technology... }\end{array}$ & Not Exploiting technology & $\begin{array}{l}\text { Slow to maximize } \\
\text { technology }\end{array}$ \\
\hline $\begin{array}{l}\text { Our processes are not consumer } \\
\text { friendly... }\end{array}$ & Not Exploiting technology & $\begin{array}{l}\text { Slow to maximize } \\
\text { technology }\end{array}$ \\
\hline
\end{tabular}

